\title{
Pollutant transport in coastal areas with and without background wind
}

\author{
J. Camps ${ }^{1}$, J. Massons ${ }^{1}$, M. R. Soler ${ }^{2}$, E. C. Nickerson ${ }^{3}$ \\ ${ }^{1}$ Applied Physics Laboratory, Universitat Rovira i Virgili, Tarragona. Spain \\ 2 Department of Astronomy and Meteorology, Universitat Barcelona, Barcelona, Spain \\ ${ }^{3}$ Forecast Systems Laboratory, NOAA, Boulder, Colorado, USA
}

Received: 10 April 1996 / Revised: 30 October 1996 / Accepted: 19 November 1996

\begin{abstract}
A three-dimensional meteorological model and a Lagrangian particle dispersion model are used to study the effects of a uniform large-scale wind on the dispersion of a non-reactive pollutant in a coastal region with complex terrain. Simulations are carried out both with and without a background wind. A comparison between model results and measured data (wind and pollutant concentrations) indicates that the coupled model system provides a useful mechanism for analyzing pollutant dispersion in coastal regions.
\end{abstract}

\section{Introduction}

Since the beginning of the numerical and experimental studies on sea breeze circulations, the influence of largescale winds on such circulations has been a subject of intense research. The first studies of this phenomenon as a function of synoptic conditions (large-scale winds, atmospheric stability, etc) were by Defant (1951) and Estoque (1962). The latter analyzed the effects of largescale winds blowing from various wind directions on the intensity and extent of the sea breeze.

The case most commonly considered corresponds to large-scale winds blowing from land to sea. Atkinson (1981) has demonstrated that in that situation the sea breeze front penetrates inland slowly and can even disappear if the thermal difference between sea and land surfaces becomes too small, or if the background wind is too strong. Several studies have recently been carried out to analyze the interactions between sea breeze and geostrophic winds. Among those are the works of Bechtold et al. (1991), and Arrit (1993).

The influence of geostrophic winds on pollutant dispersion in coastal zones, influenced by sea breeze

Correspondence to: J. Massons circulations, has also been discussed by Segal et al. (1988), Physick and Abss (1991) and Yamada et al. (1992), among others. These works conclude that pollutant dispersion is strongly influenced by background winds which have an important effect on the advection of the pollutant by modifying the thermal stability of the atmosphere and the effective stack height.

In this work, the dispersion of $\mathrm{SO}_{2}$ in a coastal zone with complex terrain is investigated using a 3-D meteorological model and a 3-D Lagrangian particle model. The meteorological model is the hydrostatic meso-beta model of Nickerson et al. (1986) which includes the parametrization of the boundary layer proposed by Bougeault and Lacarrere (1989), and the vegetation scheme of Mahfouf et al. (1987), and Pinty et al. (1989). The model also takes into account the cloud microphysics and a detailed parametrization of sulfate particles scavenging (Chaumerliac et al., 1992). Scaling arguments suggest that the hydrostatic assumption is valid when the acceleration term is smaller than the pressure gradient and buoyancy terms (Pielke, 1984; Avissar et al., 1990). Also the reasonable agreement of the results model with the observations provides a supplementary justification.

The Lagrangian model (Zannetti, 1990) follows the motion of particles released in the wind field generated by the meteorological model. The simulation was realized in the presence of a constant synoptic wind of $2.5 \mathrm{~m} / \mathrm{s}$. Results obtained have been correlated with meteorological and concentration fields modeled without background winds in order to establish the influence of large-scale motions on pollutant dispersion. Measured wind data (both at the surface and aloft) and pollutant concentration are also presented.

\section{Description of the numerical experiment}

The numerical experiment consists of a study of the land and sea breeze in the region of Tarragona, located in northeast Spain near the Mediterranean Sea (Camps 
et al., 1996). The detailed orography of the zone is depicted in Fig. 1. Relatively high mountain ranges close to the shoreline can be observed; however, in the central part of the domain there is a coastal plain. The most significant orographic features include a mountain range $(1000 \mathrm{~m})$ in the western part of the computational domain, and another range $(800 \mathrm{~m})$ in the northeast. Between those two ranges lies the Francoli River valley. Previous experimental studies (Gavaldà et al., 1992) have demonstrated that the wind regime in the zone is dominated primarily by the sea breeze, especially during the summer months.

Sea breeze circulations have been investigated for a typical summer day (27 July, 1992) using a threedimensional hydrostatic model (Nickerson et al., 1986). In addition to the prediction of the time varying wind fields, the numerical model also includes prognostic equations for the equivalent potential temperature, specific humidity and turbulent kinetic energy (order 1.5 closure). The vertical velocity component is computed from the equation of continuity. Davies's lateral boundary conditions (Davies, 1983) have been applied, using the initial boundary values as constant forcing boundary conditions.

The domain is a $140 \mathrm{~km}$ quadrant with a horizontal grid spacing of $2.5 \mathrm{~km}$. The vertical terrain-following coordinate system includes 30 computational levels, increasing resolution near the soil. For instance, in the lowest level of the model, the grid space is $4 \mathrm{~m}$. The top of model domain is assumed at $100 \mathrm{hPa}$. The model was initialized at 0400 LST (Camps et al., 1996), and the

B

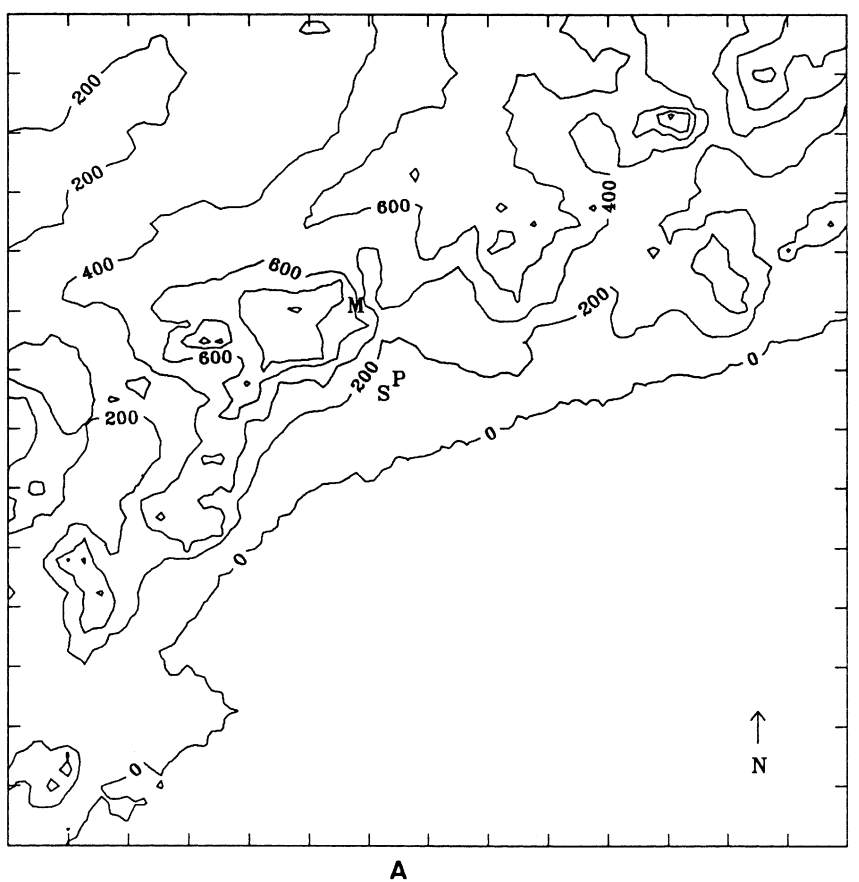

Fig. 1. Map of the analyzed region. Spacing between elevation contours is $200 \mathrm{~m}$. $P$ indicates the main source of pollutant, $M$ the surface meteorological and air quality measuring station, and $S$ corresponds to the sodar location. Divisions markers are every $10 \mathrm{~km}$ computations where carried out for a period of $24 \mathrm{~h}$. Thermodynamical variables were initialized using a summer climatological rawinsonde (Camps et al., 1996). The thermal stratification corresponds to the standard atmosphere $\left(\partial \mathrm{T} / \partial \mathrm{z} \approx-6 \mathrm{~K} \mathrm{~km}^{-1}\right)$, and the humidity varies near linearly from $12 \mathrm{~g} / \mathrm{Kg}$ at the surface to $3 \mathrm{~g} / \mathrm{Kg}$ at a height of $6 \mathrm{~km}$. The sea surface temperature remained unchanged during the simulation ( $298 \mathrm{~K})$. The temperature and moisture at the ground surface were updated every $60 \mathrm{~s}$ using an energy budget technique (Mahfouf et al., 1987; Pinty et al., 1989). The time-dependent soil model contains 13 levels in the first meter. Initial soil temperature was equal to the surface temperature and the moisture within the soil was 0.6 times that of the saturated value for each type of soil. Those values were updated during the numerical experiment using the diffusion equation. Six different land use categories were considered using the parametrization of Deardorff (1978). Calculation of solar and infrared fluxes are based on Mahfouf et al. (1987), which takes into account the influence of the slope terrain (Kondratyev, 1969).

Next, a second simulation was carried out, superimposing a large-scale background wind on the sea breeze circulation. Hereafter the first numerical experiment (without background wind) will be referred to as E1, and the simulation carried out with a large-scale flow as E2.

The background wind was defined by prescribing a geostrophic wind constant in height and time blowing from the NW. The imposed large-scale wind was $2.5 \mathrm{~m} / \mathrm{s}$, which is the geostrophic wind deduced from the $850 \mathrm{hPa}$ meteorological charts of 27 July 1992. The equations for the horizontal wind components are written as in Bechtold et al. (1991).

Surface wind fields were continuously monitored at the automatic meteorological station shown in Fig. 1 (label M). This station provides, among other parameters, surface wind velocity and direction every hour. The evaluation of the vertical profile of wind speed and direction was based on data collected by a sodar (see Fig. 1, label S). Every hour it provided $u$ and $v$ wind components from 50 to $500 \mathrm{~m}$ height.

The location of the main petrochemical plant is also shown in Fig. 1 (label P). The emission rate was assumed to be constant, at $2868 \mathrm{Kg} / \mathrm{h}$ of $\mathrm{SO}_{2}$. The effective stack height of the source was $275 \mathrm{~m}$. Both parameters remained constant during the course of the simulations.

Pollutant transport and diffusion were analyzed using a Lagrangian particle model (Zanneti, 1984). This method uses the dynamic outputs provided by the three-dimensional meteorological model to produce a particle displacement by means of the classical Markovchain scheme. So, the particle velocity is computed as a sum of auto-correlation term and a random contribution whose properties are chosen in order to ensure that the particles move in accordance with the turbulence statistics and mean wind profile (Zanetti, 1990). The meteorological parameters needed to run the particle model were obtained from the meteorological model outputs. The parameters not directly provided by the 
code (as the Lagrangian time scale) were estimated by means of the semiempirical parametrization proposed by Hanna (1982) using meteorological model outputs (mixing height, roughness length, Obukov length, friction velocity and convective velocity scale). In this way, the particles could fully incorporate the time-varying three-dimensional meteorological inputs and simulate extremely complex atmospheric diffusion conditions with a high degree of spatial and temporal resolution. In principle, this approach is grid free, since, even when meteorological input is given at grid points, each particle can move according to meteorological values that can be incorporated exactly at the particle location.

The time step used in the meteorological model was $2.5 \mathrm{~s}$. Every 20 time steps ( $50 \mathrm{~s}$ ), a set of 30 buoyant free particles were released and then moved using the wind field provided by the meteorological model. The soil was considered to be a non-absorbing surface, so that when a particle arrived at the soil, it was reflected back into the atmosphere.

Pollutant concentration fields were determined every three hours. Pollutants were released from the grid points containing the source, beginning at 0700 LST. Although $\mathrm{SO}_{2}$ shows a reactive behavior over long time scales, it can be considered as a non-reactive gas during the time interval analyzed here (two days). Evolving concentration amounts were obtained by counting the number of particles in each cell and converting that

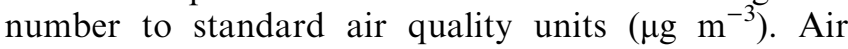
quality measurements, which include $\mathrm{SO}_{2}$ data, were recorded at the meteorological station (see Fig. 1) every hour.

Both meteorological and pollutant concentration results are shown in vertical and horizontal cross sections. The horizontal views presented in this study show values computed $4 \mathrm{~m}$ above the ground, where the distance between markers is $15 \mathrm{~km}$. Vertical views correspond to section A-B in Fig. 1. The distance between markers in the horizontal axes of those figures is $5 \mathrm{~km}$. The meteorological code and the Lagrangian particle model were run on a CRAY Y-MP, taking about $5500 \mathrm{~s}$ for three hours of simulation. The computer time depends of the number of airborne particles, which increases with time.

\section{Model results}

In order to better determine the influence of a background large-scale wind on sea breeze characteristics and pollutant dispersion trends, the results obtained in both E1 and E2 simulations are presented side by side, corresponding to the same time. Two types of plots are shown: vertical cross sections and horizontal surfaces. Cross sections correspond to vertical views in the $\mathrm{N}$ $\mathrm{S}$ planes containing Tarragona. Low level $(4 \mathrm{~m}$ height above soil) values are presented in the horizontal views. Owing to the absence of realistic time-dependent lateral boundary conditions supplied by a larger scale model, only the $30 \times 30$ central portion of the mesh is shown.

The meteorological and pollutant concentration distributions are presented at 1000 and 1900 LST because they are the most interesting in order to analyze the behavior of the sea breeze flow.

Figure 2 shows the vertical cross section of potential temperature at 1000 and 1900 LST for both the E1 and E2 cases. Figure 2a, c corresponds to the results obtained without the background wind, and Fig. $2 \mathrm{~b}, \mathrm{~d}$
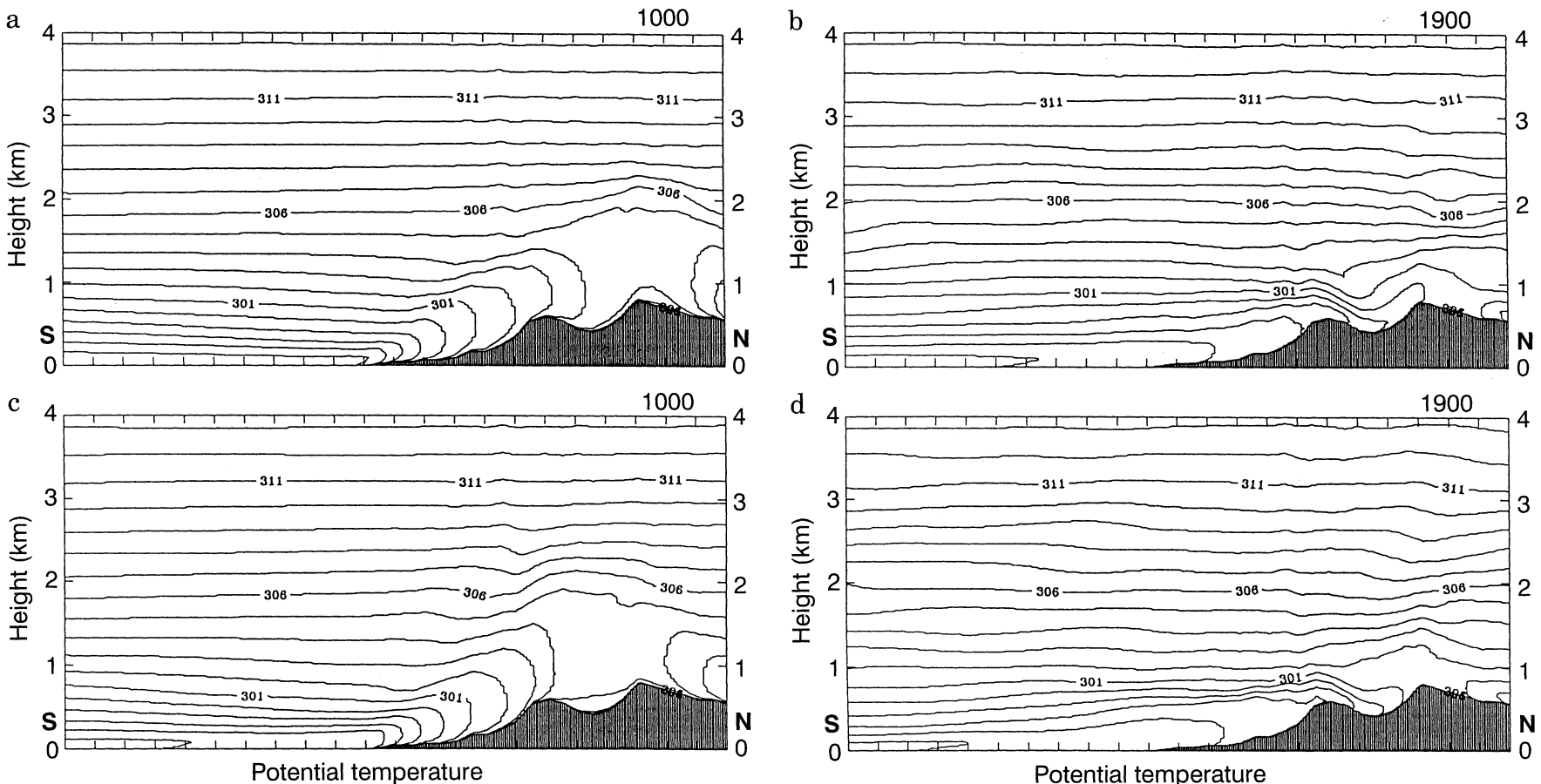

Fig. 2a-d. Vertical cross sections of potential temperature in K at a 1000 LST, E1; b 1900 LST, E1; c 1000 LST, E2; d 1900 LST, E2 
corresponds to the distributions obtained in the geostrophic case. At the beginning of the simulation, the temperature over land is nearly uniform, only varying due to altitude changes. Sunrise produces a heating of the ground producing a shallow mixed layer over land. At 1000 LST, the structure of the potential temperature field is quite similar for both analyzed cases, showing only a downstream displacement of those structures by the geostrophic wind. Both distributions show a horizontally homogeneous zone with a thin unstable convective layer close to the ground over land far from the coast. Above this layer, a neutral layer was generated which extends to $2000 \mathrm{~m}$, and above that layer the atmosphere remains stable. Over the sea the initial stability persists. The height of the thermal internal boundary layer increases with the distance from shore. For both analyzed situations, it can be observed that at 1900 LST, near sunset, the mixed layer was destroyed from below as a result of the intrusion of cold marine air at low levels. However, the geostrophic wind opposed the advection of marine air, thereby inducing a displacement of the thin unstable zone towards the coast.

Figure 3 shows a view of the S-N component of the wind velocity in the A-B vertical cross section. The S-N component is the most relevant component of the wind, due to deflection towards the north introduced by the Coriolis force acting on the sea breeze. It can be observed that at 1000 LST, the sea breeze was well established in both cases, and that for both cases, the typical four cells of northward and southward velocities were generated near the surface and aloft. The background wind reduced the inland penetration of the sea breeze, decreasing the maximum value of the wind velocity and increasing the maximum return flow. Following the definition of the inflow-layer depth of Arrit (1993), it can be observed that it was slightly reduced by the opposing flow. At 1900 LST, the flow maintains the general features previously mentioned, showing an increase in the sea breeze front's inland penetration. In the E1 case, the front reached the north slope of the second range, whereas in the E2 case, the frontal penetration was reduced by approximately $6 \mathrm{~km}$.

Figure 4 presents the vertical cross sections of vertical wind speed. A set of cells of vertical velocity resulting from the combination of the sea breeze circulation and orographic effects characterizes the combined flow in both cases. The maximum values of the vertical velocity are similar to those obtained by other authors ( $\mathrm{Lu}$ and Turco, 1995). The displacement (already observed) of the sea breeze front is indicated by the position of the maximum vertical wind velocity (Atkinson, 1981). This front is displaced towards the coastline. The effect of the background wind over the sea breeze flow can be better observed in Fig. 5. It shows the difference between the vertical component of the wind velocity without and with background wind. An enlargement corresponding to the land area is presented because it shows the greatest differences between the two cases analyzed. Two main cells can be observed in the difference field. The first one, located above the first mountain range (and so, closer to the shoreline) has negative values, due to the presence of the sea breeze front with positive values of $w$ for E2 case. The presence of the positive cell in the second mountain range can be explained by the presence of the sea breeze front in the E1 case. Also some secondary cells can be seen aloft due to the return flow. The vertical wind velocity fields are more similar at 1900
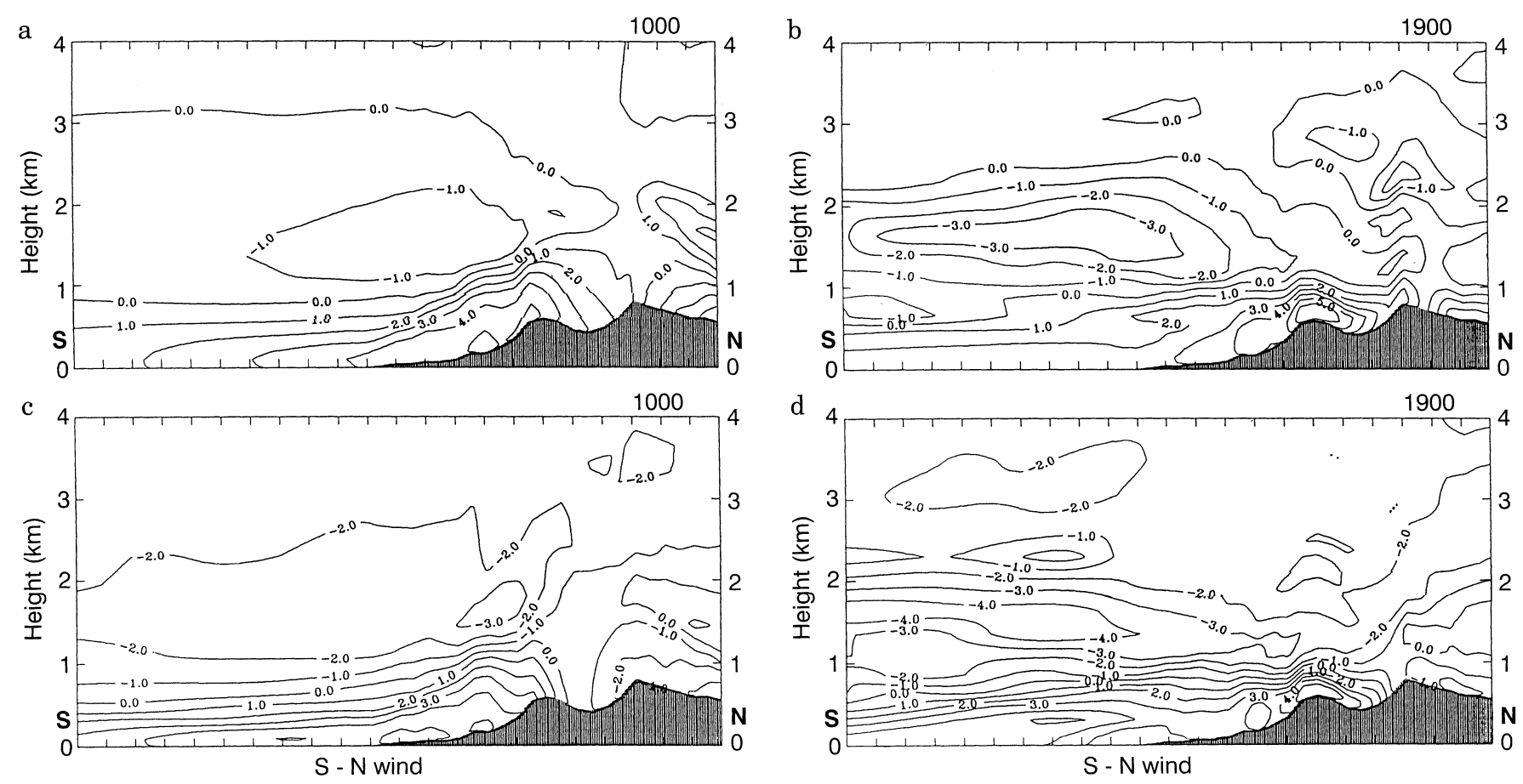

Fig. 3a-d. Vertical cross sections of S-N wind component in m/s at a 1000 LST, E1; b 1900 LST, E1; c 1000 LST, E2; d 1900 LST, E2 

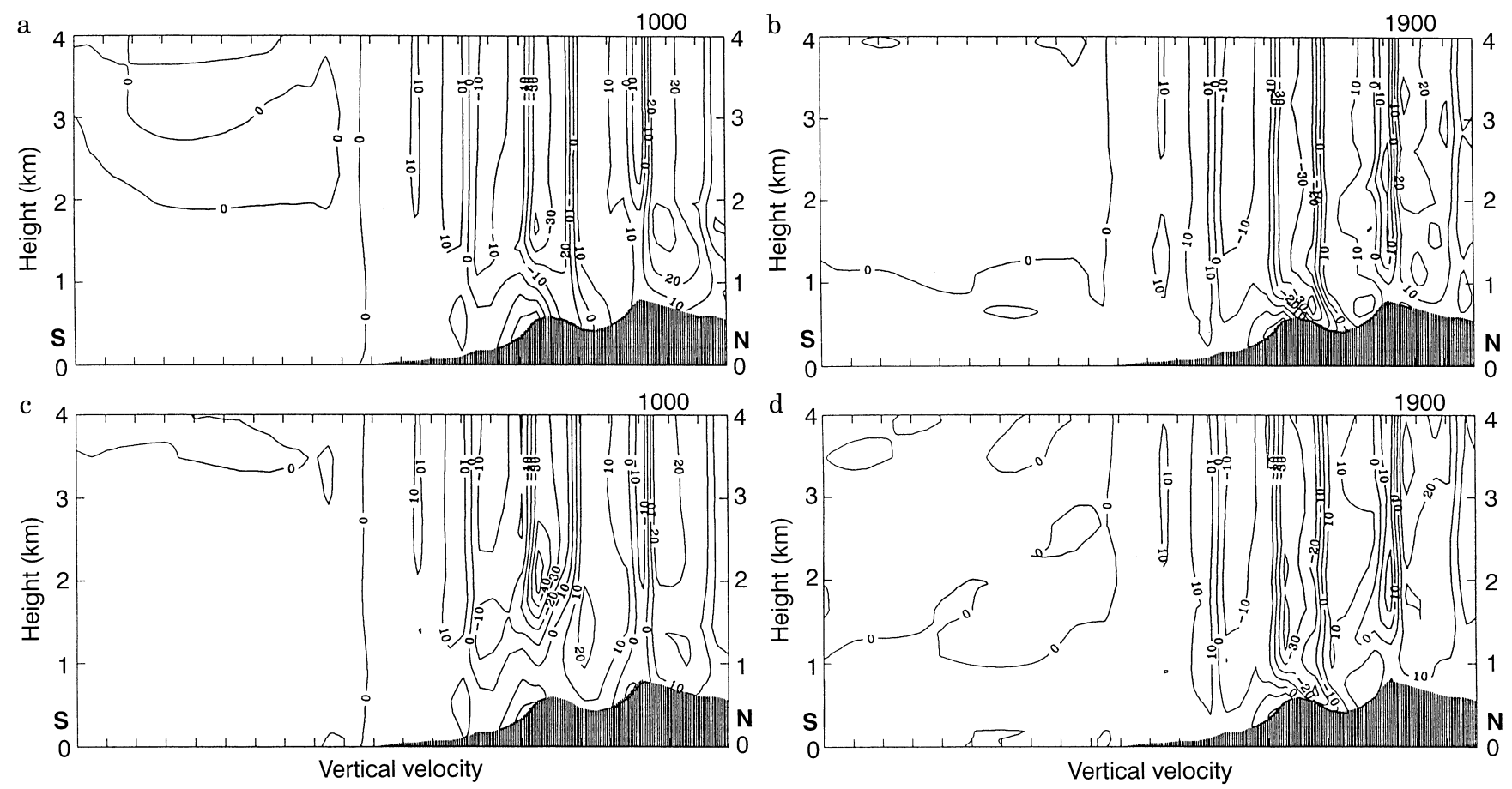

Fig. 4a-d. Vertical cross sections of vertical wind speed in cm/s at a 1000 LST, E1; b 1900 LST, E1; c 1000 LST, E2; d 1900 LST, E2

UTC (Fig. 5b) than at 1000 UTC, as indicated by the smaller values of the cell nuclei observed at 1900 UTC.

The displacement in the sea breeze front produced by the large-scale wind also implies a reduction of the speed, because in the E1 case both the sea breeze and the

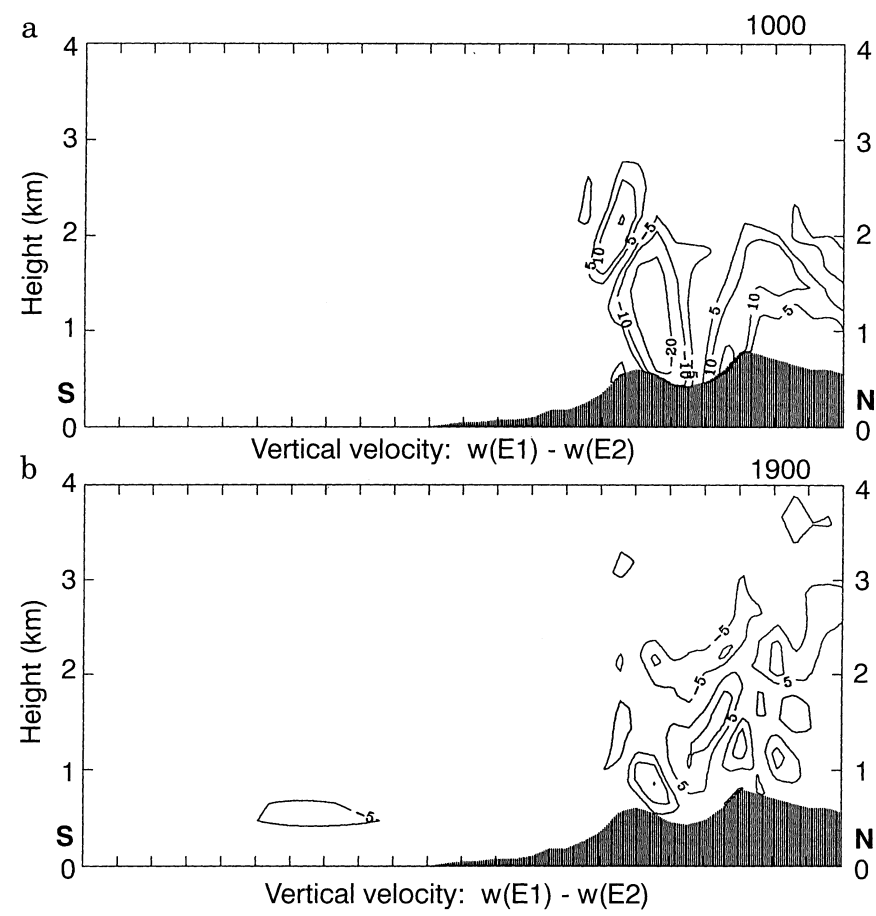

Fig. 5a, b. Vertical cross sections of differences between vertical wind speed without and with background wind in $\mathrm{cm} / \mathrm{s}$ at a $1000 \mathrm{LST}$; b 1900 LST opposing slope wind contributed to the upward flow, while in E2, the front was located in a zone with weak mountain winds. Arrit (1993), found that in flat terrain the presence of a offshore background wind increases the updraft. The results presented here show that the presence of the orography can change this conclusion substantially, leading to a reduction of the vertical speed.

Figure 6 shows the horizontal wind at the $4 \mathrm{~m}$ level corresponding to 1000 and 1900 LST for cases E1 and E2 at 4. At 1000 LST in the E1 case, the sea breeze was well established in the region near the coast. In the NW part of the domain a weak slope wind can be also observed. The maximum wind value was reached in the central part of the domain (Francoli River valley) as a result of the combination of a valley wind and the seabreeze flow. The predicted wind in the E2 case was perturbed by the large-scale flow which slightly deflected the wind toward the east. At 1900 LST the sea breeze was weaker and the flow in the Francoli River valley increased the inland penetration in both cases. This increase was less intense in the E2 case due to the effect of the geostrophic wind.

In order to correlate the measured data (both at the surface and aloft, see Fig. 1 for locations) with the computed wind field, both E1 and E2 results have been considered together. The reason is that the actual case can be considered to lie halfway between the two extreme cases: continuous presence of a geostrophic wind and the absence of a large-scale wind. Figure 7 presents a comparison between measured and computed surface winds over the full $24 \mathrm{~h}$ cycle. Figure 8 shows the vertical profiles of the $u$ and $v$ components, as modeled and observed by the sodar (see Fig. 1 for sodar lo- 


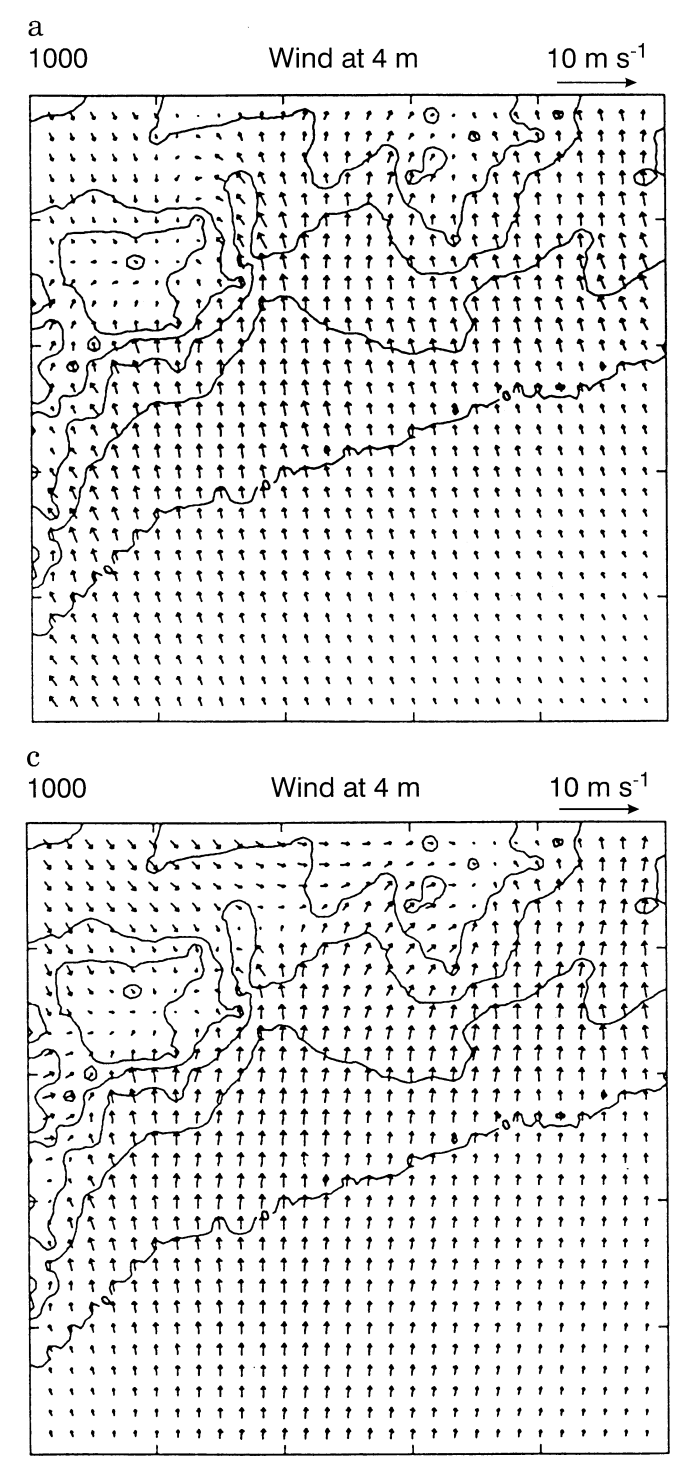

$\mathrm{b}$

$1900 \quad$ Wind at $4 \mathrm{~m} \quad 10 \mathrm{~m} \mathrm{~s}^{-1}$
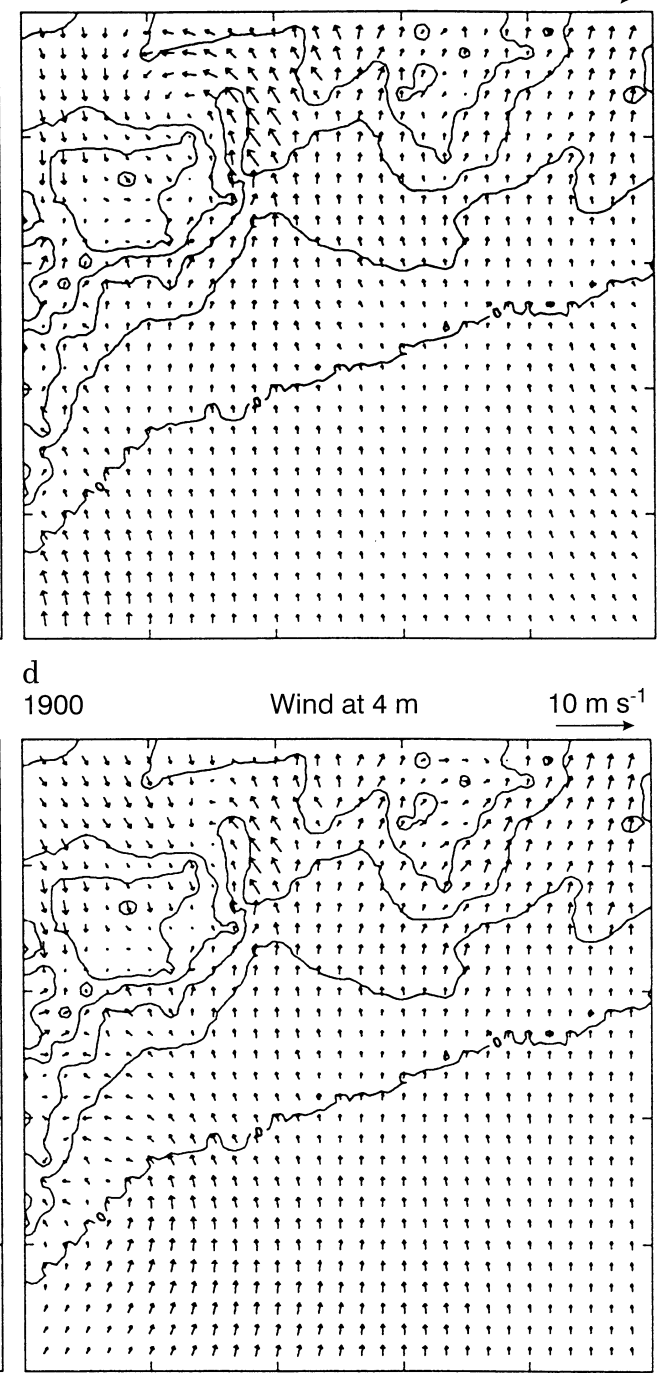

Fig. 6a-d. Horizontal velocity at $4 \mathrm{~m}$ level in $\mathrm{m} / \mathrm{s}$ at a 1000 LST, E1; b 1900 LST, E1; c 1000 LST, E2; d 1900 LST, E2

cation), at 1000 and 1900 LST. In both figures, squares indicate the results obtained in the E1 simulation, and the circles correspond to E2 case results. The comparisons show that the general behavior of the see-breeze flow was well captured by the model, giving values that agree both qualitatively and quantitatively with the measured ones. Both observed and modeled winds display a maximum in magnitude at roughly 1300 LST. It is found that the modeled winds exceeded the observed wind in both experiments. There are many sources of error affecting the accuracy of the computed wind field. Among these, the disagreement between experimental and numerically generated data can be due to inaccuracies in the initialization of the soil moisture (Mahfouf et al., 1987) as well as the coarse spatial resolution of the model which cannot resolve the details of the terrain. The land breeze flow began around 20002100 LST and was characterized by a strong reduction of the wind speed and a change in the wind direction. Those effects were well captured by the model. It is interesting to note that in the land breeze regime, the E2 experiment produced higher wind speeds than the E1 case. The wind direction is strongly influenced by local orographic features. So, in the E1 case the land breeze at the measuring station was almost normal to the coastline, whereas in the E2 case the flow became parallel to the coast, due in part to the interactions between the large-scale wind and the orography. The vertical profiles of the east-west and north-south velocity components indicate good agreement between the modeled results and the measured data. There are only minor differences between E1 and E2 results except for the $u$ component at 1000 LST, where the E2 results are considerably greater than E1 results. At that time, the $u$-component had negative values for the E1 case and positive for E2. This was due to the increase in the $u$-component introduced by the NW geostrophic wind. The $v$ component was reduced by the large-scale wind, but this reduction was not as apparent as for the $u$-component because of the larger values, even in the E1 case.

As previously stated, the pollutant concentration calculations were made in a Lagrangian framework. Virtual particles were released at regular time intervals from the source. In order to better follow the global 

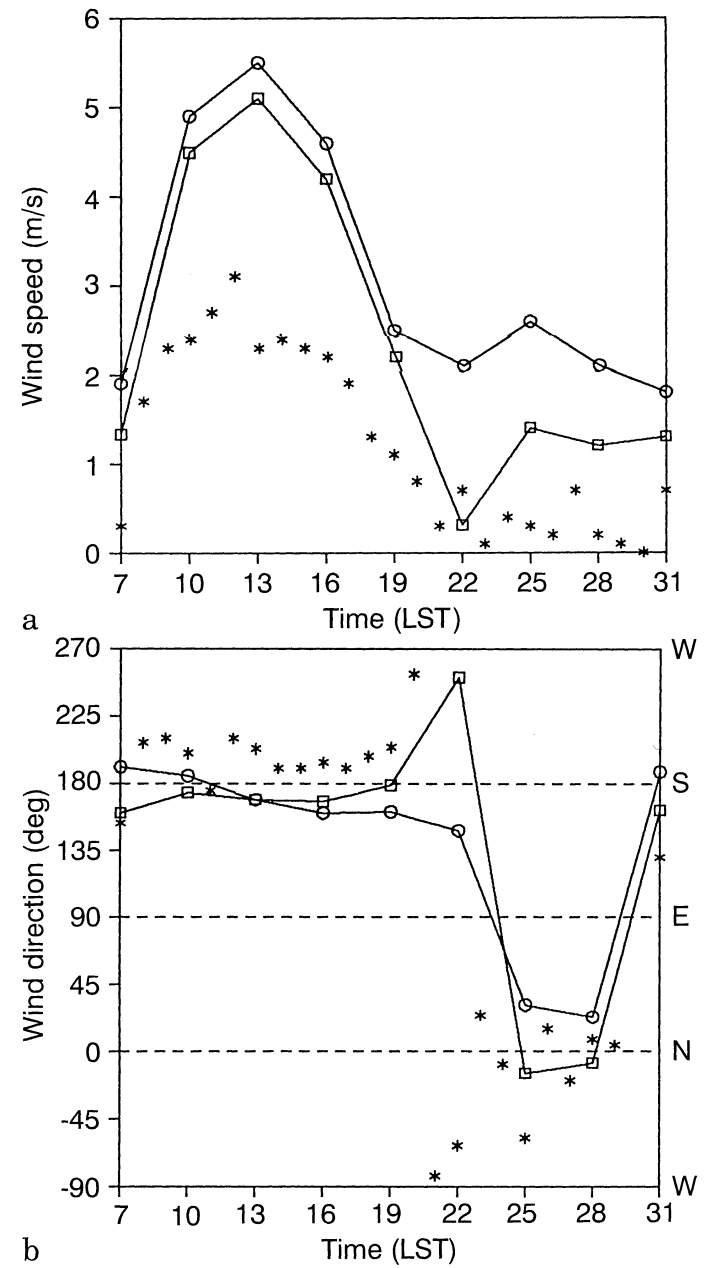

Fig. 7a, b. Time evolution of modeled and observed a wind speed and b wind direction, at the meteorological measuring station. Squares and circles show results obtained for the E1 and E2 cases, respectively. Stars indicate measured data

movement of the plume as a whole, two kinds of visualizations of particle evolutions are presented. The first corresponds to an overhead view (particle position projected on the horizontal plane), and the second corresponds to an integrated lateral view, in which the particles are projected onto the $\mathrm{SN}$ vertical plane. In this second case, a profile of the orography corresponding to section A-B (see Fig. 1) where the maximum concentraton occurred was superimposed on the visualization. In both cases, only one fourth of the particles are presented in order to enhance the clarity of the graphics. Space averaged pollutant ground level concentrations $(g l c)$ and vertical concentrations in the A-B sections are also shown. Pollutant concentration results are presented for the same times as for the meteorological data (1000 and 1900 LST).

Figures 9 and 10 show integrated views of the particle positions projected onto the vertical and horizontal planes, respectively, for both the E1 and E2 numerical experiments. It can be observed that during the daytime hours, the primary pollutant transport is inland, following the mean flow. In the horizontally integrated view, it is seen that the background wind introduced substantial modification to the particle positions. In the E1 case the plume was mainly transported northwards, following the river valley, both at the surface and aloft. The background wind caused the particles at upper levels to follow the prevailing $\mathrm{NW}$ wind. Also, the background wind reduced the pollutant penetration inland and introduced a slight deflection in the plume towards the east. In the vertical cross sections, an accumulation of particles near the source can be observed in both the E1 and E2 cases. In the E1 case, a significant concentration of particles can be found inland near the upward zone corresponding to the sea breeze front. The weak winds existing in this zone produced relatively high pollution levels, as found also by other authors (Lu and Turco, 1995). This increase of pollutant concentration is specially noticeable at 1000 LST, while at 1900, the particles were relatively well mixed due to the changes in the sea breeze dynamics. The combined effects of the background wind and the sea breeze return flow at higher elevations (E2 case) favored the advection of the particles offshore. The ambient wind increased the pollutant transport aloft, thereby inhibiting the accumulation of particles.

Figure 11 shows the ground level concentration $(g l c)$ provided by the lowest level of the model ( $4 \mathrm{~m}$ height). In both analyzed cases a northward transport is observed, clearly influenced by the orography. At 1900 LST the reduction in the wind velocity produces a more intense difussion and a substantial increase in $g l c$ in the northern part of the computational domain. Near to the source, where maximum $g l c$ is attained, the results for both analyzed cases are quite similar, both in terms of isopleth patterns and in quantitative $g l c$ values. The main differences observed between E1 and E2 lies with points far away from the source. As can be appreciated, in the E2 case the plume is deflected towards the east, following the combined flow, producing and increasing of glc in the northeast of the domain and a substantial reduction in the northwest area. Also, the inland penetration of the pollutant is inhibited by the largescale flow.

In Figure 12, the modeled concentration values for the E1 and E2 cases are compared with values measured in the air quality measuring station, located to the northwest of the source (see Fig. 1). The displacement offset between the numerical and experimental results is a consequence of the presence of background pollutant concentration $\left(15 \mathrm{\mu g} \mathrm{m}^{-3}\right)$ in the real case, which was not considered in the computer simulations. The model was initialized with a clear atmosphere, without background concentration, in order to facilitate the interpretation of the pollutant transport.

The modeled concentrations depict similar behavior in both E1 and E2 simulations, but the maximum concentration (reached between 0400 and 0700 LST) is greater in the E1 case, and is reached later than if a large-scale wind is imposed. This minor differences can be justified by the fact that the large-scale wind blows the pollutant southeastwards reducing the concentration at the measuring station also producing a delay in the 

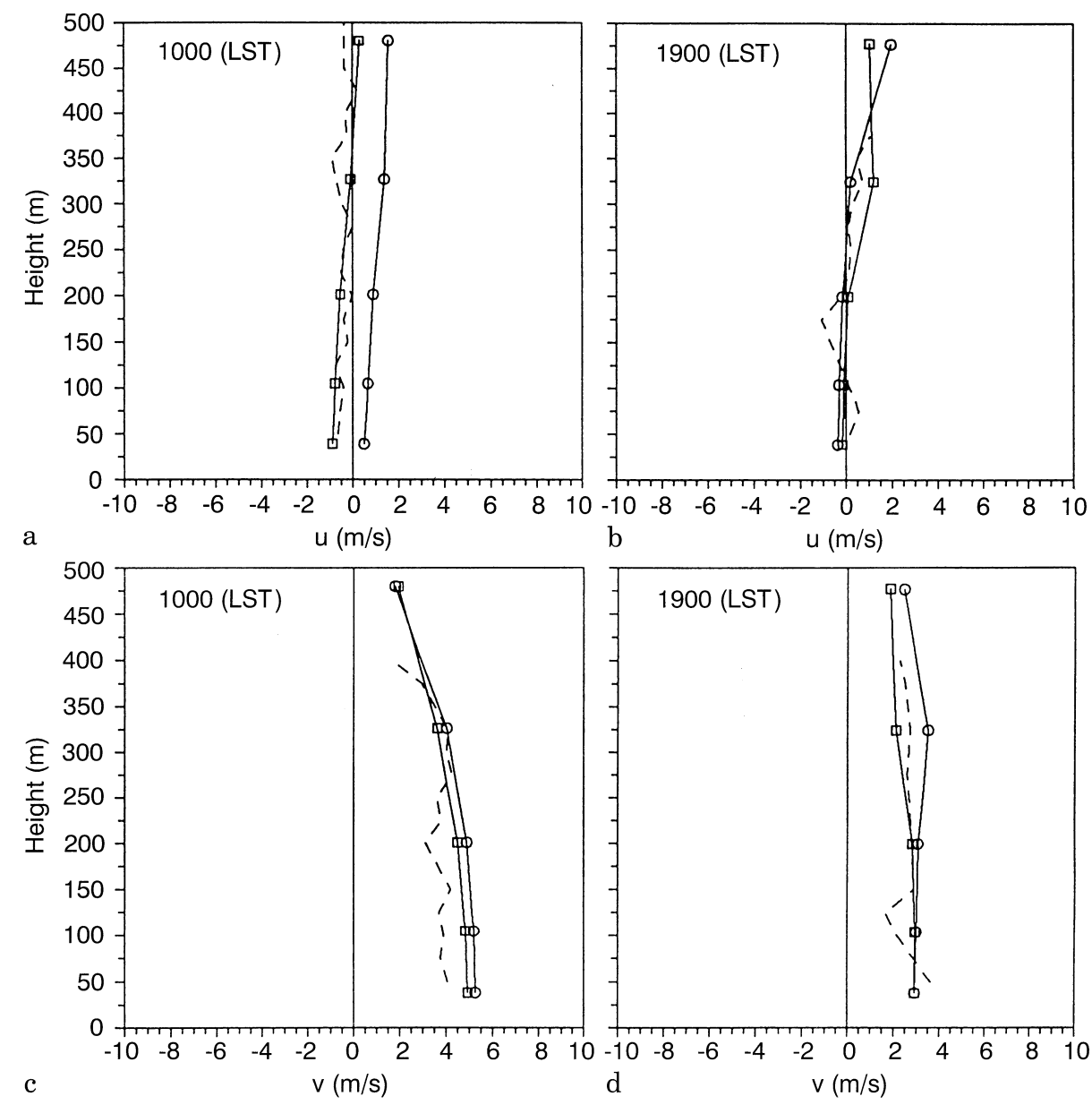

Fig. 8a-d. Vertical profiles of $u$ and $v$ wind velocity components, at the sodar location. a 1000 LST, $u$; b 1900 LST, $u$; $\mathbf{c}$ 1000 LST, $v$; d 1900 LST, v. Squares and circles show results obtained for the E1 and E2 cases, respectively. The dashed line is the sodar measured profile

arrival of the pollution compared to the E1 case. The comparison between experimental and numerical results indicates that the observations lie somewhere between the results of the two numerical simulations, E1 and E2, both with respect to the time of occurrence of maximum concentration and the magnitude of increase in the pollutant concentration above background values.

In a previous work (Camps et al., 1996), the pollutant dispersion in the analyzed area under similar sea breeze conditions was computed using an Eulerian approach. In that case the advection-diffusion equation was solved at each time step using the instantaneous wind field. Comparing the results obtained using both approaches, a similar behavior of the plume dispersion is found. Although a more intense lateral diffusion appears near the source in the Eulerian case. The time evolution of the $g l c$ obtained using the Lagrangian approach compares better with the measured data than the results obtained using the Eulerian scheme. The latter produces $g l c$ values which are much greater than the measured ones.

\section{Conclusions}

A three-dimensional hydrostatic model coupled to a Lagrangian particle dispersion model has been used to study the influence of a large-scale background wind on the pollutant dispersion in complex terrain. The presence of a moderate opposing synoptic flow was found to inhibit the inland penetration of the sea breeze and increase the speed of the return flow. A downstream displacement of the circulation with the geostrophic wind was also observed in all the results. The influence of the large-scale wind on the pollutant dispersion was especially intense in the return flow. The Lagrangian model performs well in simulating the pollutant dispersion and correctly captured the main features of the phenomenon. Modeled results of ground level pollutant concentration have been compared with measured data. Measured $g l c$ shows a background concentration which is not considered in the numerical experience but the modeled and observed excess of glc depict similar trends.

Acknowledgements. The authors would like to thank the Departament Medi Ambient, Generalitat de Catalunya, for supporting this study. Computer resources provided by CESCA are gratefully acknowledged.

Topical Editor L. Eymard thanks N. Chaumerliac and another referee for their help in evaluating this paper. 

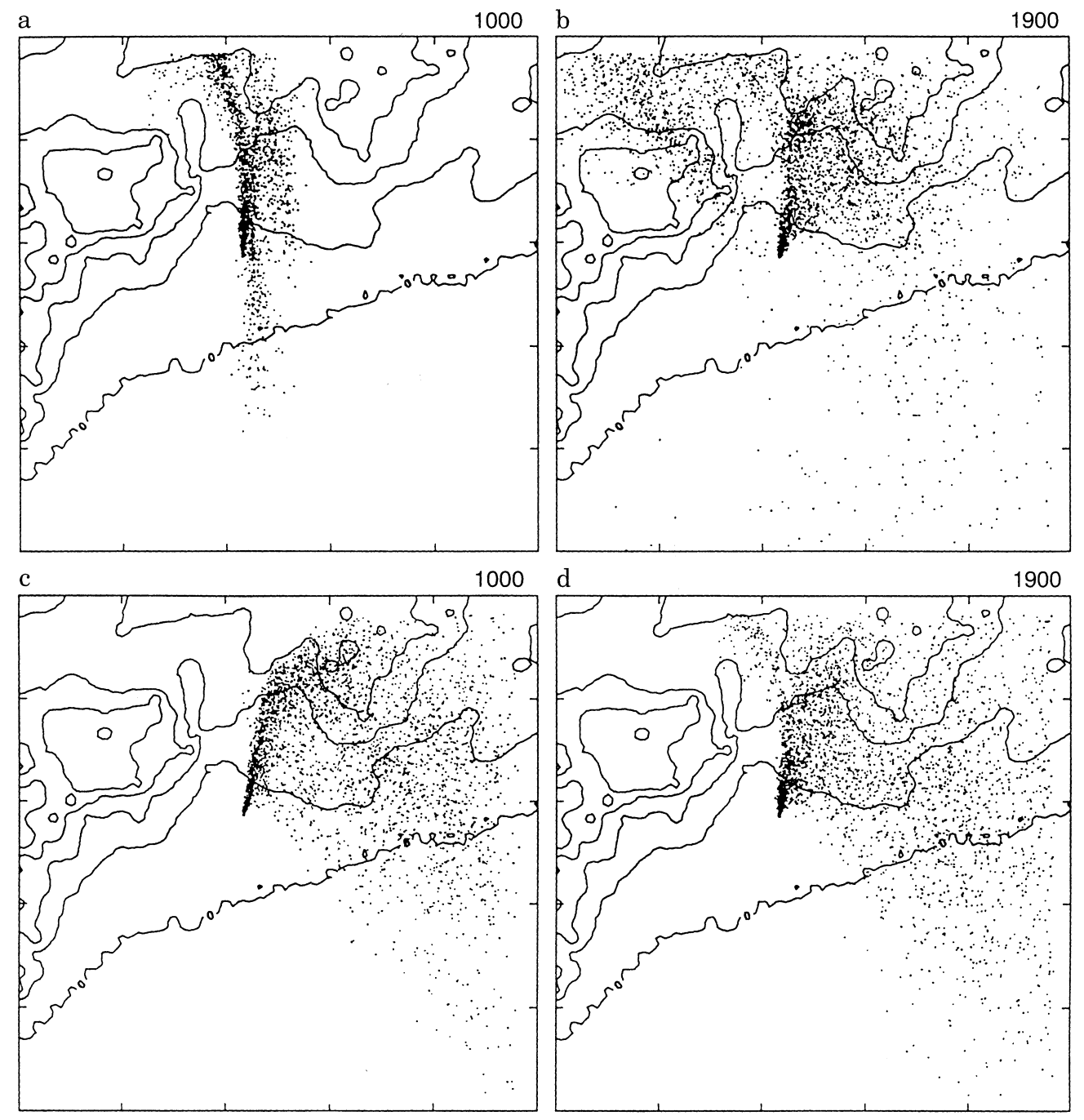

Fig. 9a-d. Integrated particle position distribution (overhead view) for a $1000 \mathrm{LST}, \mathrm{E} 1$; b 1900 LST, E1; c 1000 LST, E2; d 1900 LST, E2
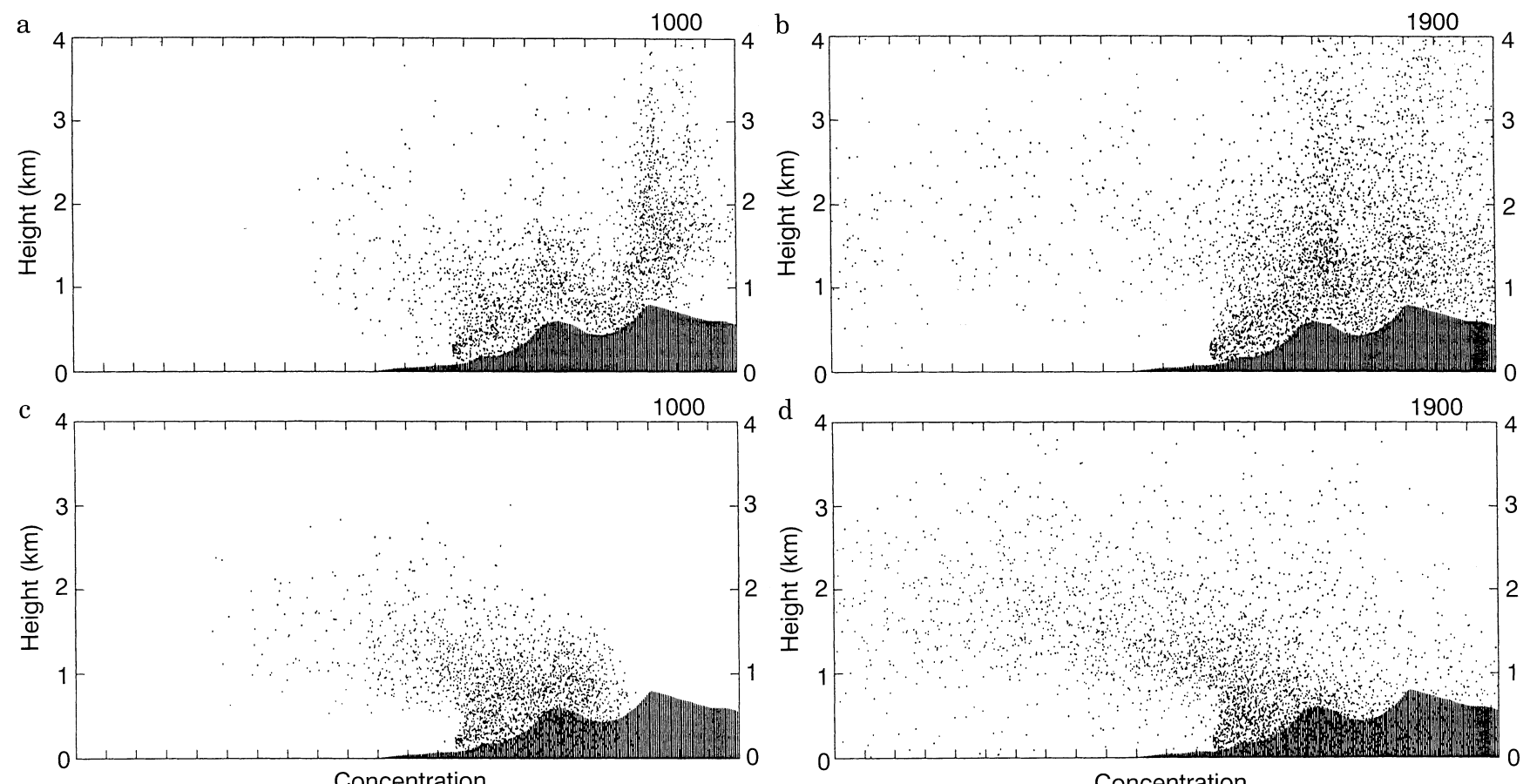

Fig. 10a-d. Integrated particle position distribution (lateral view) for a 1000 LST, E1; b 1900 LST, E1; c 1000 LST, E2; d 1900 LST, E2 

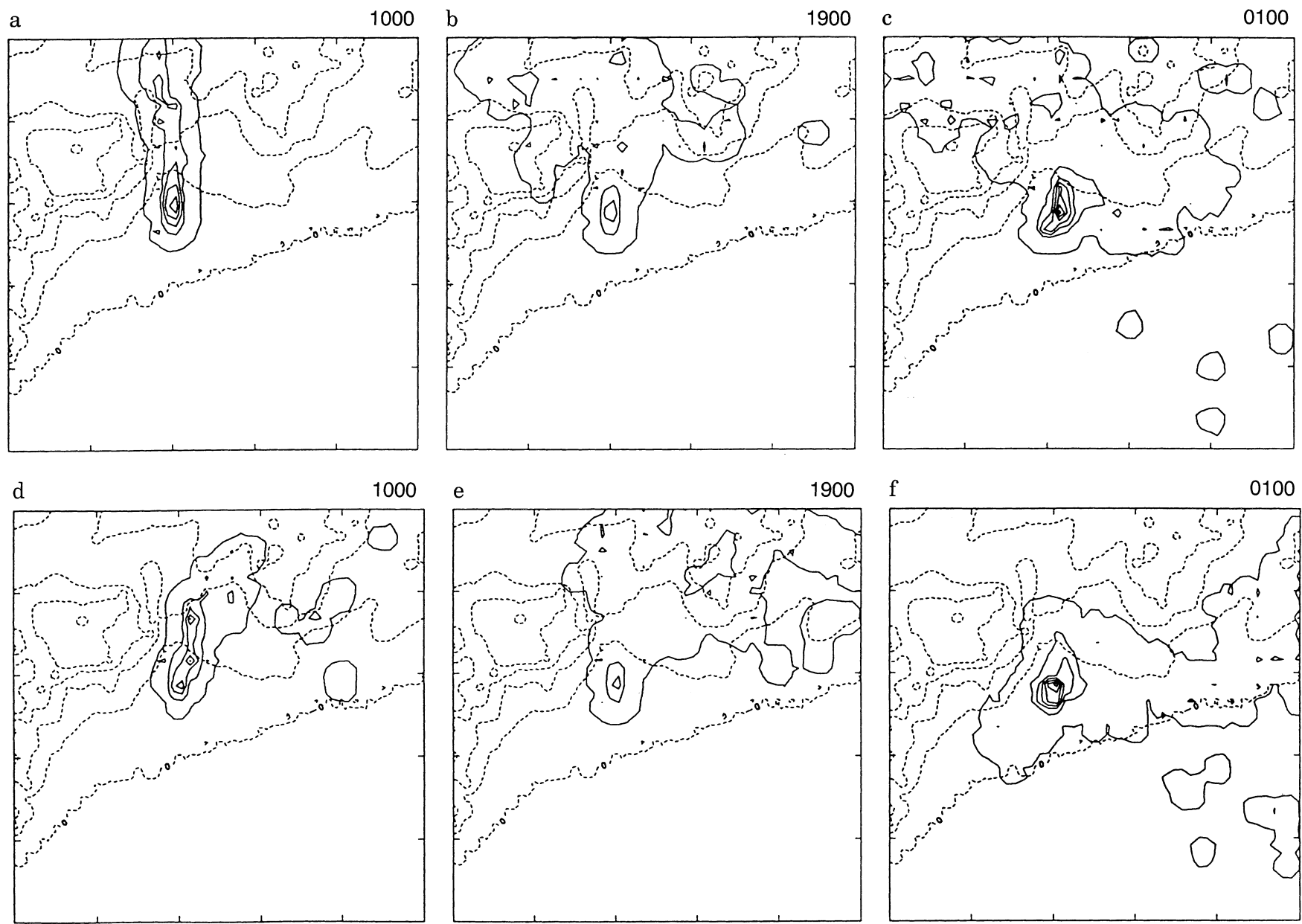

Fig. 11a-f. Ground level concentration for a 1000 LST, E1; b 1900 LST, E1; c 0100 LST, E1; d 1000 LST, E2; e 1900 LST, E2; f 0100 LST, E2. Contour concentration starts at $1 \mu \mathrm{g} \mathrm{m}^{-3}$ and the interval is $20 \mu \mathrm{g} \mathrm{m}^{-3}$ at $10 \mathrm{LST}$ and $50 \mu \mathrm{g} \mathrm{m}^{-3}$ at 1900 and 0100 LST

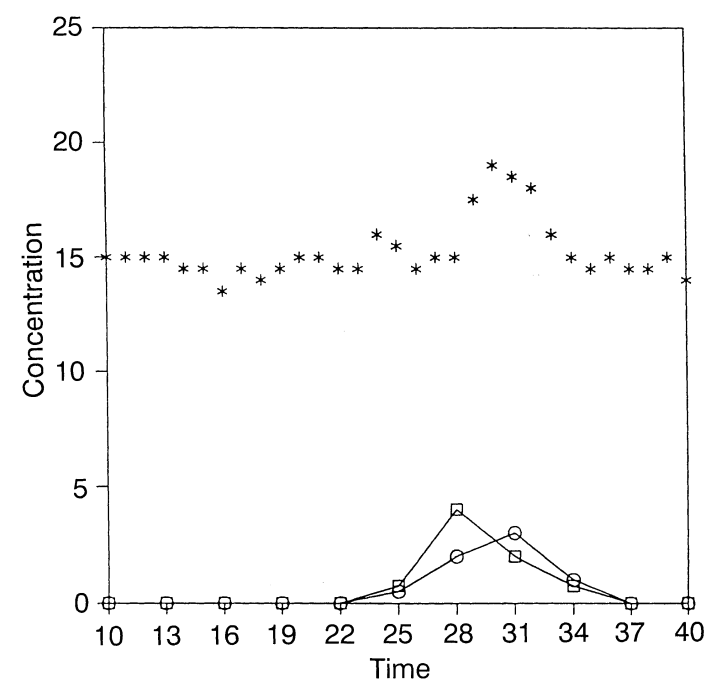

Fig. 12. Time evolution of pollutant concentration $\left(\mu \mathrm{g} \mathrm{m}^{-3}\right)$ measured (stars) and modeled (squares-E1, circles-E2) at the meteorological station

\section{References}

Arrit, R. W., Effects of the large-scale flow on characteristic features of the sea breeze, J. Appl. Meteorol., 32, 116-125, 1993.

Atkinson, B.W., Meso-scale atmospheric circulations, Academic Press, London, 1981.

Avissar, R., M. D. Moran, G. Wu, R. N. Meroney, and R.A. Pielke, Operating ranges of mesoscale numerical models and meteorological wind tunnels for the simulation of sea and land breezes, Boundary-Layer Meteorol., 50, 227-275, 1990.

Bechtold, P., J. -P. Pinty, and P. Mascart, A numerical investigation of the influence of large-scale winds on sea-breeze and inland-breeze-type circulations, J. Appl. Meteorol., 30, 1268$1279,1991$.

Bougeault, P., and P. Lacarrere, Parametrization of orography induced turbulence in a mesobeta-scale model, Mon. Weather Rev., 117, 1872-1890, 1989.

Camps, J., J. Massons, and M. R. Soler, Numerical modelling of pollutant dispersion in sea breeze conditions, Ann. Geophysicae, 14, 665-677, 1996.

Chaumerliac, N., E. Richard, J. -P. Pinty, and E. C. Nickerson, Sulfur scavenging in a mesoscale model with quasi-spectral microphysics: two-dimensional results for continental and maritime clouds, J. Geophys. Res., 92, 3114-3126, 1987.

Davies, H. C., Limitations of some common lateral boundary schemes used in regional NWP models, Mon. Weather Rev., 111, 1002-1012, 1983. 
Deardorff, J. W., Efficient prediction of ground surface temperature and moisture, with inclusion of a layer of vegetation, J. Geophys. Res., 83, 1889-1903, 1978.

Defant, F., Local winds, in Compendium of meteorology, American Meteorological Society, pp. 655-672, 1951.

Estoque, M.A., The sea breeze as a function of the prevailing synoptic situation, J. Atmos. Sci., 19, 244-250, 1962.

Gavaldà, J., J. Massons, J. Camps, and F. Díaz, Statistical and spectral analysis of the wind regime in the area of Catalonia, Theor. Appl. Climatol., 46, 143-152, 1992.

Hanna, R. S., Applications in air pollution modelling, in Atmospheric turbulence and air pollution modelling, Eds. F. T. M. Nieuwstadt, H. van Dop, D. Reidel Publishing, pp. 275-310, 1982.

Kondratyev, J., Radiation in the atmosphere, Academic Press, New York, 1969

Lu, R., and R.P. Turco, Air pollutant transport in a coastal environment-II. Three-dimensional simulations over Los Angeles basin, Atmos. Environ., 29, 1499-1518, 1995.

Mahfouf, J. -F., E. Richard, and P. Mascart, The influence of soil and vegetation on the development on mesoscale circulations, J. Clim. Appl. Meteorol., 26, 1483-1495, 1987.

Nickerson, E.C., E. Richard, R. Rosset, and D.R. Smith, The numerical simulation of clouds, rain and airflow over the Vosges and Black Forest mountains: a meso- $\beta$ model with parameterized microphysics, Mon. Weather Rev., 114, 398-414, 1986.

Physick, W. L., and D. J. Abbs, Modeling of summertime flow and dispersion in the coastal terrain of southeastern Australia, Mon. Weather Rev., 119, 1014-1030, 1991.

Pielke, R. A., Mesoscale meteorological modeling, Academic Press, New York, 1984.

Pinty, J. -P., P. Mascart, E. Richard, and R. Rosset, An investigation of mesoscale flows induced by vegetation inhomogeneities using an evapotranspiration model calibrated against HAPEX-MOBILHY data, J. Appl. Meteorol. 28, 976992, 1989.

Segal, M., R. A. Pielke, R. W. Arrit, M. D. Moran, C. -H. Yu, and D. Henderson, Application of a mesoscale atmospheric dispersion modeling system to the estimation of $\mathrm{SO}_{2}$ concentrations from major elevated sources in southern Florida, Atmos. Environ., 22, 1319-1334, 1988.

Yamada, T., S. Bunker and M. Moss, Numerical simulations of atmospheric transport and diffusion over coastal complex terrain, J. Appl. Meteorol., 31, 565-578, 1992.

Zannetti, P., New Monte Carlo scheme for simulating Lagrangian particle diffusion with wind shear effects, Appl. Math. Model., 8, 188-192, 1984.

Zannetti, P., Air pollution modelling, Van Nostrand Reinhold, New York, 1900. 